\title{
Corrigendum
}

Diabetes Metab J 2022;46:164

https://doi.org/10.4093/dmj.2022.0025

pISSN 2233-6079 • eISSN 2233-6087

\section{Association between Changes in Anthropometric Indices and in Fasting Insulin Levels among Healthy Korean Adolescents: The JS High School Study}

Ji Hye Park ${ }^{1,2}$, Seyeon Mun ${ }^{1}$, Dong Phil Choi ${ }^{3}$, Joo Young Lee ${ }^{4}$, Hyeon Chang Kim ${ }^{2,5}$

${ }^{1}$ Department of Public Health, Yonsei University Graduate School, Seoul,

${ }^{2}$ Cardiovascular and Metabolic Diseases Etiology Research Center, Yonsei University College of Medicine, Seoul,

${ }^{3}$ National Academy of Agricultural Science, Rural Development Administration, Wanju,

${ }^{4}$ Department of Medical and Pharmaceutical Affairs, Mapo-gu Health Center, Seoul,

${ }^{5}$ Department of Preventive Medicine, Yonsei University College of Medicine, Seoul, Korea

Diabetes Metab J 2019;43:183-191. https://doi.org/10.4093/dmj.2018.0034

Grant No. described in the ACKNOWLEDGMENTS section of the current manuscript has an error.

Grant No. should be changed to (No. 2010-0007860, No. 2015R1D1A-1A09057301, 2018R1D1A1A09083826)

from (No. 2010-0007860, No. 2015R1D1A-1A09057301).

We apologize for any inconvenience that this may have caused.

This is an Open Access article distributed under the terms of the Creative Commons Attribution Non-Commercial License (https://creativecommons.org/licenses/by-nc/4.0/) which permits unrestricted non-commercial use, distribution, and reproduction in any medium, provided the original work is properly cited. 